\title{
Play it again, Sam? Versioning in the market for second-hand video game \\ software
}

\begin{abstract}
Information goods are characterised by high fixed costs and low marginal costs of production. A potentially effective strategy which can be adopted by firms operating in such markets is versioning, whereby various features are added or subtracted from a number of distinct versions of the good. This effectively serves as a means of second degree price discrimination designed to extract prices closer to the maximum willingness to pay from different groups of consumers. This study tests the effectiveness of versioning as a means of exploiting differences in willingness to pay in second-hand markets for information goods by undertaking the first hedonic price analysis of video gaming software. The empirical evidence presented in this paper is based on the analysis of an extensive cross-sectional dataset consisting of over five thousand observations of pre-owned video game prices in the US. Controls are introduced for a variety of other observable characteristics, including the quality of the game-play experience, the publisher, genre and theme of the game. The results are consistent with theoretical expectations and demonstrate significant variations in willingness to pay can be exploited through the strategic use of versioning. The practice is therefore argued to represent an effective means by which firms in these markets can enhance revenues.
\end{abstract}

Keywords: Video games; versioning; information goods; hedonic pricing

JEL Codes: D4; D12; L11; Z1 


\section{Introduction}

Video gaming has rapidly evolved into a major force in the global entertainment sector. In 2015, annual revenues from the worldwide video games market were estimated to be approximately $\$ 91$ billion, with around \$22 billion of this total generated in the US alone (NewZoo, 2015). The size and rate of growth of the market for video games exceeds those of many other mainstream forms of entertainment, such as music and movies. By way of illustration, Guinness World Records recently confirmed that the game Grand Theft Auto V achieved a record-setting $\$ 816$ million in worldwide sales during the first 24 hours of release ("Confirmed", 2013). This figure represents the highest revenue ever generated by the launch of an entertainment product and comfortably exceeds earnings from Star Wars: The Force Awakens, which at the time of writing holds the current worldwide boxoffice record as a result of generating \$529 million during its opening weekend in December 2015 (“All Time Box Office”, 2015).

In theoretical terms, video gaming software is an obvious example of an information good, which is defined in terms of high fixed costs of production and negligible marginal costs. Economic theory on pricing of information goods outlined in the seminal work of Varian (1995) and developed in studies by Anderson \& Dana (2009); Bhargava \& Choudhary (2001a, 2001b, 2008); Linde (2009); Shapiro \& Varian (1998) and Varian (2000; 2001) highlights how a special kind of second-degree price discrimination known as versioning or quality differentiation can be particularly effective in such markets. The practice involves releasing different versions of the same underlying product, thereby encouraging consumers to 'self-select' in accordance with their willingness-to-pay (WTP). This has the obvious potential to enhance profits, even in the somewhat perverse case where producers incur costs in degrading the quality of 'high WTP' products for sale to the low WTP market.

The aim of this paper is to investigate variations in consumer WTP resulting from versioning through the analysis of data from the market for used video games. The reason for this particular focus is that 
new software tends to be sold at a set RRP which is more-or-less constant for each hardware platform and means that consumer demand typically adjusts to meet a fixed price. However, prices of used video games are able to vary to a far greater extent in response to variations in demand; essentially allowing free market valuations of titles according to variations in consumer WTP. The specific research question to be addressed is therefore 'to what extent does consumer WTP for video game software vary in the presence of versioning'? In addressing this question, the study offers unique evidence on the extent to which versioning is likely to lead to enhanced revenues for video game publishers. Further, the analysis is intended to serve as a useful aid to strategic decision making with respect to the effective use of versioning, both in this particular context and in other markets for information goods.

The remainder of the paper is structured as follows. Section 2 contains a discussion of the data and methods used in this study, while Section 3 outlines the empirical findings. Section 4 then presents a summary of the conclusions of the study, as well as the managerial implications for software developers and publishers.

\section{Data and method}

The previous section introduced the concept of the versioning of information goods and highlighted how the practice can be revenue (and profit) enhancing so long as two or more consumer groups exist with significant differences in their WTP. This section outlines the approach used in this study to test the extent to which these assumptions hold in a market context where price is effectively unrestricted and hence allowed to vary to a greater extent in response to variations in consumer WTP. The market for pre-owned video gaming software in the US is of considerable strategic importance to video games publishers, being valued at somewhere between $\$ 2$ - $\$ 3$ billion annually, with over 47 million

people in the US purchasing one or more used titles each year (J.J. Games, 2010). Several major retailers have a significant presence in this market; most notably Gamestop, which generates around 
half of their gross profits from the sale of pre-owned video games ("Gamestop continues run", 2013), as well as Wal-Mart, Best Buy, Toys R Us and Amazon. The used market is highly attractive to retailers because they are able to retain $100 \%$ of the sale price, whereas royalties have to be paid to developers and publishers on the sale of new titles. For this reason, the resale of video gaming software has been strongly resisted by firms further up the supply chain, with several employing a range of strategies specifically designed to curtail such activity. For example, Electronic Arts (EA) have previously distributed single use access codes along with new copies of games that would allow access to online multiplayer features. If the game was subsequently resold in the second-hand market, the new owner had to purchase another access code directly from the publisher in order to unlock those aspects of the game. Another notable case relates to Microsoft, who initially intended to employ technical restrictions for its Xbox One console that would block the use of second-hand titles entirely. In both cases, the firms involved were forced to back-track on these measures due to significant PR backlash.

In order to address the primary research question of this study, a dataset containing a cross-section of prices for used video games titles was collected in August 2010. The data are sampled across a number of hardware platforms, with original release dates ranging from the mid-1990s up to the present day. Price data are obtained from BRE Software's Game Price Guide Online ${ }^{1}$, which catalogues over 15,000 pre-owned video game prices and is updated three times a week. The dataset also includes information on a range of observable control characteristics relating to each title that could plausibly explain variation in market prices. In the context of addressing the aim of this particular study, the most crucial characteristic is whether or not the game is a 'special edition' (i.e. a version designed to appeal to high value consumers). The BRE price guide also contains information on the platform of release and whether the game comes bundled with a physical peripheral or accessory; each of these factors are controlled for in the empirical analysis.

\footnotetext{
${ }^{1}$ http://gamepriceguide.net/
} 
Additional supplementary information for each title was extracted from the Video Games Database maintained by MobyGames ${ }^{2}$. This information includes platform of release, censorship rating, maximum number of players allowed simultaneously and the timing of release, both in absolute terms and relative to the appropriate hardware platform. Controls are also included for publisher and genre, as well as a measure of the opinion expressed by professional critics to serve as a proxy for underlying quality. In the same way films or books are subject to widespread critical attention in the popular media, video games are scrutinised by critics via specialist press appearing both in print and online. Studies such as Combris et al. (1997) have chosen to exclude similar information from their hedonic price estimation of Bordeaux wine on the grounds that the critical response to an experience good is not a relevant inclusion, as purchasing occurs before tasting takes place. However, this study argues that review scores from professional critics are a valid inclusion in the price estimation, as they represent an observable characteristic known to consumers in advance of purchase. Review scores are obtained from the Metacritic website ${ }^{3}$, which supplies a 'metascore' out of 100 for an extensive catalogue of video games based on the weighted average of review scores published by a variety of printed and online sources around the world.

The relevant categories and specific variables included in the empirical analysis are summarised in Table 1 and have mostly been coded in dichotomous terms, with mean and standard deviations reported where appropriate. After filtering the data and eliminating a small number of outliers from the remaining sample (39 such observations are identified, accounting for approximately $0.7 \%$ of the sample), the final number of observations used in the empirical analysis is 5,118. In particular, it should be noted that the mean value of the 'Special Edition' variable $(0.025)$ is relatively small, indicating somewhat limited use of versioning in this particular market during the time period under analysis. However, the data clearly show an increase in the number of special edition variants captured by the dataset over time. Less than $1 \%$ of the titles sampled titles from 2000-2004 were

\footnotetext{
${ }^{2}$ http://www.mobygames.com/

${ }^{3}$ http://www.metacritic.com/
} 
special editions, while the proportion increases to $6 \%$ for $2008-2009$ and $9 \%$ for 2010 . Given that there is no reason to suspect any bias in the sampling of data, this trend is likely to indicate an increase in the use of the practice over time. Conversely, this pattern may also support the contention that premium editions are more likely to be kept by their original owners, whereas standard editions are disproportionately resold.

\section{[Table 1 about here]}

Using these data, a hedonic pricing analysis is undertaken in order to empirically estimate variations in consumer WTP for used video games. The hedonic approach is based upon the premise that the value of a good is a direct function of its objectively quantifiable utility-bearing characteristics (Lancaster, 1966) and that these characteristics are essentially traded in bundles within implicit markets (Rosen, 1974). However, a particular issue surrounding the application of hedonic pricing analysis where utility from consumption is not known with certainty ex ante is that a wealth of relevant characteristics can be difficult to describe and hence are not easily quantifiable (Oliner \& Sichel, 1994; Hollanders \& Meijers, 2002). Despite these inherent difficulties, hedonic pricing analysis has previously been applied to computer software in studies such as Gandal (1994); Brynjolfsson \& Kemerer (1996); Harhoff \& Moch (1997); Castranova (2004); Prud'homme et al. (2005) and Chakravarty et al. (2006). However, as far as the author is aware, this is the first study to undertake a hedonic pricing analysis based on the characteristics of video gaming software.

The data described in Table 1 are fed into a hedonic pricing estimation model, which is specified in Equation (1):

InPrice $_{i}=\beta_{0}+\beta_{1}$ SpecialEdition $_{i}+\beta_{2}$ Review $_{i}+\beta_{3}$ Rating $_{i}+\beta_{4}$ Age $_{i}+\beta_{5}$ MaxPlayers $_{i}+\beta_{6}$ Online $_{i}+$

$\beta_{7 \text { Licensed }_{i}}+\beta_{8}$ Accessory $_{i}+\beta_{9 \text { Multiplatform }_{i}}+\beta_{10}$ Console $_{i}+\beta_{11}$ Genre $_{i}+\beta_{12}$ Developer $_{i}+\varepsilon_{i}$

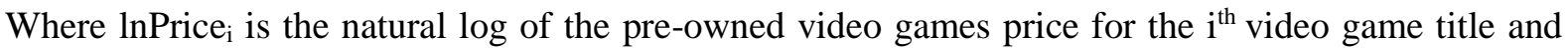
Rating, Console, Genre and Publisher are vectors containing a variety of dummy variables designed to capture the presence or absence of relevant features for each title within these stated categories. Other 
variables represent individual title characteristics as described in Table 1. Of specific interest is the estimated value of $\beta_{1}$, which provides evidence on the extent to which versioning exploits differences WTP among consumers and leads to significant variation in the value of pre-owned video games.

\section{Results}

Table 2 presents estimation output from two different regression models. Specification (i) follows the functional form outlined in Equation (1), while Specification (ii) includes a number of additional interaction terms. In both cases, the dependent variable is the natural log of the pre-owned game price and so coefficients can be interpreted as percentage changes in price resulting from a one unit change in the respective independent variable. Where a majority of these variables are dichotomous, the stated coefficient can be interpreted as the given percentage variation in price associated with the presence of this characteristic. Heteroskedasticity consistent standard errors are reported and used to determine the statistical significance of parameter estimates.

[Table 2 about here]

In specification (i), a majority of the general characteristic variables are statistically significant at or above the $95 \%$ confidence level. The $\mathrm{R}^{2}$ value is approximately 0.58 , which shows that the model provides a reasonably good explanation for the variation in the data in the context of a hedonic regression. Other than the clear heterogeneity of prices between hardware platforms, the other largest variations in price are observed for special editions and games that come bundled with an accessory, which respectively add thirty-nine per cent and sixty-two per cent to the value of a title. The large and positive coefficient attached to the former suggests significantly variation in WTP between high and low value groups in the presence of versioning. This further implies that versioning is indeed an effective strategy by which publishers can encourage consumers to 'self-select' into different groups as a means by which to enhance revenues. The positive and comparatively large coefficient estimated for titles that come bundled with an accessory is to be expected, since the consumer would be paying 
not only for the software itself, but also for a physical peripheral (such as a mock-instrument, special controller etc.) which itself has an intrinsic value.

The estimated coefficients for the other characteristic variables are mostly in accordance with theoretical expectations, with a few notable exceptions. The presence of a title on multiple gaming platforms and licensed titles are each typically valued at around six per cent less than the respective alternatives. This suggests that consumers in this market value platform exclusivity and games based on original concepts. Online features are also found to associate negatively and significantly with WTP, such that market value is reduced by around ten per cent when an online multiplayer mode is offered. These findings are somewhat surprising in the presence of potential network externalities associated with the consumption of these goods, given that platform exclusivity obviously restricts the size of the installed user base. Furthermore, the presence of an online multiplayer mode allowing the opportunity to connect with other players represents a utility enhancing characteristic, which should resultantly associate with a higher WTP. One possible explanation for the latter finding is that the appeal of online play may significantly diminish once games reach the second hand market. If online interest and activity is disproportionately clustered around the latest releases, players of older titles may resultantly struggle to find opponents in sufficient quantity and regularity, hence decreasing WTP for this feature. Finally, when measured relative to other maturity ratings, games that are rated as suitable for teen players are associated with prices that are approximately two per cent higher relative to games suitable for all ages. Games with a mature rating associate negatively with price, but the estimated coefficient is not statistically significant. As mentioned above, dummy variables which reflect the hardware platform of release are found to universally exert a significant influence on price, with signs and magnitudes that are entirely in line with expectations ${ }^{4}$.

\footnotetext{
${ }^{4}$ An obvious question to raise at this time would be the suitability of running single regressions based on the common sample, when the evidence clearly suggests that pre-owned software prices are strongly influenced by the gaming platform for which the title appears. The same regression analysis is conducted on separate sub-samples of the data, organised by console and the estimated coefficients attached to each of the other variables included in the model are virtually unchanged. Thus, for expositional clarity, only results of the estimations run on the common sample are included in this report although these separate regressions add a measure of reassurance regarding the robustness of the parameter estimates.
} 
In terms of variables designed to control for the more subjective qualities of each title, the model output suggests that the quality of a game has a relatively small but significant influence on its market value. The magnitude of the coefficient suggests that the market price of pre-owned video games is relatively inelastic to variations in quality, as a one per cent increase in the Metacritic rating is estimated to increase the value of a typical game by just under half of one per cent. This is somewhat surprising given the significant influence that quality is seen to have on sales of new video games (Cox, 2014) and suggests that quality is a less important determinant of demand in the second hand market. Around half of the dummy variables representing games released by major publishers are significant at or above the ninety-five per cent confidence interval, suggesting that several major publishers have the potential to significantly add (or subtract) value from pre-owned video games. Five of the seven genre dummy variables are also found to be statistically significant, suggesting clear heterogeneity in the value of games based on content, design etc.

Specification (ii) includes interaction terms between key model variables; specifically, age, special edition and review score. While these results present a negative coefficient estimate for the special edition variable, this is not found to be statistically significant from zero at the $95 \%$ confidence level. Instead, this result should be considered alongside the (significantly positive) coefficient estimated for the interaction between the special edition variable and the review score, which unsurprisingly indicates that special editions of more highly rated (better quality) titles tend to command higher used values than special editions of less highly rated titles. Furthermore, the negative coefficient capturing the relationship between special editions and the age of a title indicates that special editions are likely to decline in value over time, suggesting that second-hand demand is greatest for special editions of newer titles. Finally, a relatively small negative relationship is estimated for the coefficient capturing interaction between the age of an individual and the review score implies that critical response has a diminishing influence on price as individual titles become older. In other words, the smaller than anticipated association between review scores and used software prices could potentially be caused by a consumer's own experience 'superseding' reviews from professional critics; an effect which seems to grow stronger as individual titles age over time. Aside from these specific insights, the inclusion of 
interaction terms has only a modest effect upon the model diagnostics, while the estimated coefficients of non-interacted variables remain largely consistent with previously reported values.

\section{Summary and Managerial Implications}

This paper uses a hedonic price estimation to analyse the effective use of versioning in the second hand market for information goods, while also controlling for an extensive range of other factors affecting the demand for pre-owned video games. The results highlight several key factors that explain variations in pre-owned video games prices, not least of which relate to the effect of versioning on consumer WTP. Special edition variants of particular titles, as well as games released for newer platforms or that come packaged with an accessory, associate with significantly higher values. In contrast, the market attaches a lower value to licensed and cross-platform titles, as well as those with online multiplayer modes. Significant heterogeneity is also observed in the demand for games across hardware platforms, publishers and genres.

These findings provide empirical evidence in support of the theory relating to the effectiveness of versioning in markets for information goods; particularly those with the potential for significant network externalities (Jing, 2000). Additionally, these findings also have several significant managerial implications for video game publishers. First, as a result of the significantly higher WTP observed among consumers of premium content, it is suggested that video games publishers might enhance revenues by operating a more widespread policy of second-degree price discrimination. Indeed, given the significant variation in consumer WTP observed between premium and nonpremium versions of the same game, an obvious potential exists for releasing a broader selection of versions for each product. This would have the potential of encouraging self-selection and exploiting variations in WTP between, for example, high, medium and low value consumers, as opposed to simply high and low. 
Second, assuming that publishers perceive the sale of pre-owned video games as a threat to revenues, these findings highlight how various strategies are likely to lead to reduced WTP within the used market. Obvious examples are the decreases in WTP found to associate with multi-platform releases and the inclusion of online functionality. Publishers are therefore recommended to focus on releasing their titles on multiple platforms, as well as integrating online multiplayer modes into their games as much as possible. Firms may be able to supress demand in second hand markets through strategic provision of online functionality and expediting the withdrawal of online support for their older games following the release of newer titles. 


\section{References}

All Time Box Office: Worldwide Openings. (2015). Retrieved from the Box Office Mojo Website: http://boxofficemojo.com/alltime/world/worldwideopenings.htm

Anderson, E.T. \& Dana, J. (2009). When is price discrimination profitable? Management Science, 55(6), 980-989.

Bhargava, H.K. \& Choudhary, V. (2001a). Information goods and vertical differentiation. Journal of Management Information Systems, 18(2), 89-106.

Bhargava, H.K. \& Choudhary, V. (2001b). Second-degree price discrimination and information goods under non-linear utility functions. Proceeds of the $34^{\text {th }}$ Annual Hawaii International Conference on Systems Sciences, Vol. 7, IEE Computer Society, Washington DC.

Bhargava \& Choudhary, V. (2008). When is versioning optimal for information goods? Management Science, 54(5), 1029-1035.

Brynjolfsson, E. \& Kemerer, C. (1996). Network externalities in microcomputer software: An econometric analysis of the spreadsheet market. Management Science, 42 (12): 1627-1647.

Castronova, E. (2004). The price of bodies: A hedonic pricing model of avatar attributes in a synthetic world. KYKLOS, 57(2), 173-196.

Chakravarty, S., Dogan, K. \& Tomlinson, N. (2006). A hedonic study of network effects in the market for word processing software. Decision Support Systems, 41, 747-763.

Combris, P., Lecocq, S. \& Visser, M. (1997). Estimation of a hedonic price equation for Bordeaux wine: Does quality matter? The Economic Journal, 107, 390-402.

Confirmed: Grand Theft Auto 5 Breaks 6 Sales World Records. (2013). Retrieved from the Guinness World Records Website: http://www.guinnessworldrecords.com/news/2013/10/confirmed-grandtheft-auto-breaks-six-sales-world-records-51900/ 
Cox, J. (2014). What makes a blockbuster video game? An empirical analysis of US sales data. Managerial and Decision Economics, 35(3), 189-198.

Gamestop continues run after Microsoft capitulates on used games. (2013). Retrieved from the Forbes website: http://www.forbes.com/sites/greatspeculations/2013/06/24/gamestop-continues-run-aftermicrosoft-capitulates-on-used-games/

Gandal, N. (1994). Hedonic price indexes for spreadsheets and an empirical test of the network externalities hypothesis. RAND Journal of Economics, 25(1): 160-170.

Harhoff, D. \& Moch, D. (1997). Price indexes for PC database software and the value of code compatibility. Research Policy, 26(4-5), 509-520.

Hollanders, H. \& Meijers, H. (2002). Quality adjusted prices and software investments: The use of hedonic price indexes. New Indicators for the Knowledge Based Economy.

Jing, B. (2000). Versioning information goods with network externalities. ICIS Proceedings, Paper 1.

J.J. Games Report (2010). The used video games market, July 2010.

Lancaster, K.J. (1966). A new approach to consumer theory. Journal of Political Economy, 74, 132156.

Linde, F. (2009). Pricing information goods. Journal of Product \& Brand Management, 18(5), 379384.

NewZoo. (2015). Top 100 countries by game revenues 2015. Retrieved from: http://www.newzoo.com/free/rankings/top-100-countries-by-game-revenues/

Oliner, S.D.\& Sichel, D.E. (1994). Computers and output growth revisited: How big is the puzzle? Brookings Papers on Economic Activity, 2, 273-317.

Prud'homme, M., Sanga, D. \& Yu, K. (2005). A computer software price index using scanner data. Canadian Journal of Economics, 38(3), 999-1117. 
Rosen, S. (1976). Hedonic prices and implicit markets: Product differentiation in pure competition. Journal of Political Economy, 82(1), 34-55.

Shapiro, C. \& Varian, H. (1998). Versioning: The smart way to sell information. Harvard Business Review, November-December, 92-105.

Varian, H. (1995). Pricing information goods. In: Symposium on scholarship of the new information environment proceedings, Research Libraries Group, Harvard Law School, Cambridge, MA.

Varian, H. (2000). Buying, sharing and renting information goods. Journal of Industrial Economics, 48(4), 473-488.

Varian, H. (2001). Versioning information goods. In: Kahin, B. \& Varian, H. (eds.) Internet publishing and beyond: The economics of digital information and intellectual property, MIT Press, Cambridge MA. 
Tables and Figures

\begin{tabular}{|c|c|c|c|c|}
\hline Variable Name & Description & Mean (Std. Dev.) & Min & Max \\
\hline \multicolumn{5}{|c|}{ GENERAL CHARACTERISTICS } \\
\hline PRICE & Quoted market used price in USD & $15.79(9.669)$ & 2.95 & 179.95 \\
\hline SPECIALEDITION & Game is listed as a special edition & 0.025 & 0 & 1 \\
\hline REVIEW & Review score from Metacritic (/100) & $69.283(13.679)$ & 12 & 98 \\
\hline AGE & Age of game (years) at time of data collection & $4.870(2.464)$ & 0 & 10 \\
\hline MAXPLAYERS & Maximum number of players in offline mode & $1.849(1.313)$ & 1 & 8 \\
\hline ONLINE & Game allows for online play via the internet & 0.206 & 0 & 1 \\
\hline LICENSED & Game content/characters are licensed (film, TV etc.) & 0.398 & 0 & 1 \\
\hline ACCESSORY & Game comes with an accessory (instrument etc.) & 0.022 & 0 & 1 \\
\hline MULTIPLATFORM & Game appears on more than one console (non-exclusive title) & 0.524 & 0 & 1 \\
\hline \multicolumn{5}{|c|}{ RATINGS (Mutually Exclusive, Non-exhaustive) } \\
\hline RATINGT & Game has been awarded a Teen rating & 0.324 & 0 & 1 \\
\hline RATINGM & Game has been awarded a Mature rating & 0.152 & 0 & 1 \\
\hline \multicolumn{5}{|c|}{ CONSOLE (Mutually Exclusive, Exhaustive) } \\
\hline GBA & Game is for the Nintendo Gameboy Advance system & 0.093 & 0 & 1 \\
\hline $\mathrm{GCN}$ & Game is for the Nintendo Gamecube system & 0.095 & 0 & 1 \\
\hline NDS & Game is for the Nintendo DS system & 0.089 & 0 & 1 \\
\hline WII & Game is for the Nintendo Wii system & 0.065 & 0 & 1 \\
\hline PS2 & Game is for the Sony Playstation 2 system (BASE CASE) & 0.269 & 0 & 1 \\
\hline PS3 & Game is for the Sony Playstation 3 system & 0.073 & 0 & 1 \\
\hline PSP & Game is for the Sony Playstation Portable system & 0.064 & 0 & 1 \\
\hline XBOX & Game is for the Microsoft XBox system & 0.151 & 0 & 1 \\
\hline X360 & Game is for the Microsoft Xbox 360 system & 0.103 & 0 & 1 \\
\hline \multicolumn{5}{|c|}{ GENRE (Non-mutually Exclusive, Exhaustive) } \\
\hline ACTION & Game is of the action genre (BASE CASE) & 0.625 & 0 & 1 \\
\hline ADVENTURE & Game is of the adventure genre & 0.068 & 0 & 1 \\
\hline EDUCATIONAL & Game is of the educational genre & 0.006 & 0 & 1 \\
\hline RACING & Game is of the racing genre & 0.141 & 0 & 1 \\
\hline RPG & Game is of the role-playing game genre & 0.111 & 0 & 1 \\
\hline SIMULATION & Game is of the simulation genre & 0.093 & 0 & 1 \\
\hline STRATEGY & Game is of the strategy genre & 0.100 & 0 & 1 \\
\hline SPORTS & Game is of the sports genre & 0.211 & 0 & 1 \\
\hline \multicolumn{5}{|c|}{ PUBLISHER (Mutually Exclusive, Non-exhaustive) } \\
\hline $2 \mathrm{~K}$ & Game is published by $2 \mathrm{~K}$ Games & 0.021 & 0 & 1 \\
\hline ACCLAIM & Game is published by Acclaim & 0.017 & 0 & 1 \\
\hline ACTIVISION & Game is published by Activision & 0.082 & 0 & 1 \\
\hline ATARI & Game is published by Atari & 0.027 & 0 & 1 \\
\hline CAPCOM & Game is published by Capcom & 0.040 & 0 & 1 \\
\hline DISNEY & Game is published by Disney Games & 0.008 & 0 & 1 \\
\hline EIDOS & Game is published by Eidos Interactive & 0.021 & 0 & 1 \\
\hline EA & Game is published by Electronic Arts & 0.131 & 0 & 1 \\
\hline INFOGRAME & Game is published by Infograme & 0.010 & 0 & 1 \\
\hline KONAMI & Game is published by Konami & 0.047 & 0 & 1 \\
\hline MICROSOFT & Game is published by Microsoft & 0.022 & 0 & 1 \\
\hline MIDWAY & Game is published by Midway Games & 0.030 & 0 & 1 \\
\hline NAMCO & Game is published by Namco & 0.032 & 0 & 1 \\
\hline NINTENDO & Game is published by Nintendo & 0.047 & 0 & 1 \\
\hline ROCKSTAR & Game is published by Rockstar Games & 0.012 & 0 & 1 \\
\hline SONY & Game is published by Sony & 0.047 & 0 & 1 \\
\hline SEGA & Game is published by Sega & 0.053 & 0 & 1 \\
\hline THQ & Game is published by THQ & 0.061 & 0 & 1 \\
\hline SQUAREENIX & Game is published by Square Enix & 0.014 & 0 & 1 \\
\hline UBISOFT & Game is published by Ubisoft & 0.058 & 0 & 1 \\
\hline
\end{tabular}




\begin{tabular}{|c|c|c|c|c|}
\hline Specification & (i) & & (ii) & \\
\hline Variable Name & $\begin{array}{l}\text { Coefficient } \\
\text { (Std. Error) }\end{array}$ & & $\begin{array}{l}\text { Coefficient } \\
\text { (Std. Error) }\end{array}$ & \\
\hline \multicolumn{5}{|l|}{ GENERAL CHARACTERISTICS } \\
\hline CONSTANT TERM & $1.912(0.032)$ & $* *$ & $2.258(0.058)$ & $* *$ \\
\hline SPECIALEDITION & $0.394(0.032)$ & $* *$ & $-0.219(0.222)$ & \\
\hline REVIEW & $0.004(0.000)$ & $* *$ & $0.010(0.001)$ & $* *$ \\
\hline AGE & $0.065(0.009)$ & $* *$ & $0.009(0.004)$ & \\
\hline MAXPLAYERS & $0.008(0.004)$ & & $0.008(0.004)$ & \\
\hline ONLINE & $-0.098(0.014)$ & $* *$ & $-0.101(0.014)$ & $* *$ \\
\hline LICENSED & $-0.060(0.011)$ & $* *$ & $-0.055(0.011)$ & $* *$ \\
\hline ACCESSORY & $0.616(0.044)$ & $* *$ & $0.605(0.043)$ & $* *$ \\
\hline MULTIPLATFORM & $-0.061(0.012)$ & $* *$ & $-0.065(0.011)$ & $* *$ \\
\hline \multicolumn{5}{|l|}{ RATINGS } \\
\hline RATINGT & $0.024(0.012)$ & $*$ & $0.024(0.012)$ & $*$ \\
\hline RATINGM & $-0.020(0.016)$ & & $-0.020(0.016)$ & \\
\hline \multicolumn{5}{|l|}{ PLATFORM } \\
\hline GBA & $0.124(0.020)$ & $* *$ & $0.051(0.021)$ & ** \\
\hline GCN & $0.297(0.018)$ & $* *$ & $0.227(0.018)$ & $* *$ \\
\hline NDS & $0.397(0.033)$ & $* *$ & $0.137(0.020)$ & $* *$ \\
\hline WII & $0.670(0.051)$ & $* *$ & $0.283(0.023)$ & $* *$ \\
\hline PS3 & $0.774(0.022)$ & $* *$ & $0.363(0.023)$ & $* *$ \\
\hline PSP & $0.463(0.035)$ & $* *$ & $0.203(0.021)$ & $* *$ \\
\hline XBOX & $-0.183(0.018)$ & $* *$ & $-0.249(0.017)$ & $* *$ \\
\hline X360 & $0.612(0.045)$ & $* *$ & $0.274(0.022)$ & $* *$ \\
\hline \multicolumn{5}{|l|}{ GENRE } \\
\hline ADVENTURE & $0.024(0.019)$ & & $0.030(0.019)$ & \\
\hline EDUCATIONAL & $0.003(0.073)$ & & $0.000(0.073)$ & \\
\hline RACING & $0.035(0.014)$ & $*$ & $0.036(0.014)$ & $*$ \\
\hline RPG & $0.113(0.016)$ & $* *$ & $0.109(0.016)$ & $* *$ \\
\hline SIMULATION & $0.068(0.018)$ & $* *$ & $0.067(0.018)$ & $* *$ \\
\hline STRATEGY & $0.037(0.017)$ & $*$ & $0.038(0.017)$ & $*$ \\
\hline SPORTS & $-0.164(0.014)$ & $* *$ & $-0.159(0.014)$ & $* *$ \\
\hline \multicolumn{5}{|l|}{ DEVELOPER } \\
\hline $2 \mathrm{~K}$ & $-0.169(0.040)$ & $* *$ & $-0.176(0.039)$ & $* *$ \\
\hline ACCLAIM & $-0.060(0.036)$ & & $-0.075(0.035)$ & $*$ \\
\hline ACTIVISION & $-0.002(0.019)$ & & $-0.005(0.020)$ & \\
\hline ATARI & $-0.058(0.032)$ & & $-0.054(0.033)$ & \\
\hline CAPCOM & $0.009(0.024)$ & & $0.009(0.024)$ & \\
\hline DISNEY & $-0.208(0.058)$ & $* *$ & $-0.196(0.057)$ & $* *$ \\
\hline EIDOS & $-0.075(0.025)$ & $* *$ & $-0.077(0.025)$ & $* *$ \\
\hline EA & $-0.107(0.018)$ & $* *$ & $-0.100(0.017)$ & ** \\
\hline INFOGRAME & $0.105(0.017)$ & $*$ & $0.097(0.052)$ & \\
\hline KONAMI & $0.094(0.023)$ & $* *$ & $0.089(0.023)$ & $* *$ \\
\hline MICROSOFT & $-0.194(0.035)$ & $* *$ & $-0.198(0.034)$ & $* *$ \\
\hline MIDWAY & $-0.016(0.027)$ & & $-0.014(0.027)$ & \\
\hline NAMCO & $0.074(0.029)$ & $* *$ & $0.079(0.029)$ & $* *$ \\
\hline NINTENDO & $0.129(0.026)$ & $* *$ & $0.135(0.026)$ & $* *$ \\
\hline ROCKSTAR & $-0.110(0.044)$ & $*$ & $-0.123(0.042)$ & ** \\
\hline SONY & $-0.078(0.025)$ & $* *$ & $-0.084(0.025)$ & $* *$ \\
\hline SEGA & $-0.020(0.023)$ & & $-0.003(0.023)$ & \\
\hline THQ & $-0.004(0.020)$ & & $-0.009(0.019)$ & \\
\hline SQUAREENIX & $-0.007(0.037)$ & & $-0.014(0.037)$ & \\
\hline UBISOFT & $-0.027(0.021)$ & & $-0.025(0.021)$ & \\
\hline \multicolumn{5}{|l|}{ INTERACTION TERMS } \\
\hline SPECIALEDITION x REVIEW & - & & $0.010(0.003)$ & ** \\
\hline SPECIALEDITION x AGE & - & & $-0.076(0.021)$ & $* *$ \\
\hline REVIEW $\times$ AGE & - & & $-0.001(0.000)$ & $* *$ \\
\hline R Squared & 0.580 & & 0.590 & \\
\hline $\mathrm{F}$ & 151.252 & $* *$ & 149.110 & $* *$ \\
\hline $\mathrm{N}$ & 5078 & & 5078 & \\
\hline
\end{tabular}

